\title{
Deep Atmosphere of Venus Probe as a Mission Priority for the Upcoming Decade
}

AUTHOR: James B. Garvin

NASA's Goddard Space Flight Center

Email: james.b.garvin@nasa.gov

Phone (cell): 301-646-4369

C0-AUTHORS: Giada N. Arney (NASA GSFC) Sushil Atreya (Univ. Michigan)

Stephanie Getty (NASA GSFC)

CO-SIGNEES: Michael Amato (NASA GSFC)

Bruce Campbell

(NASM, Smithsonian)

Dave Crisp (NASA JPL)

Scott Guzewich (NASA GSFC)

Sarah Horst (JHU/APL)
Martha Gilmore (Wesleyan)

David Grinspoon (PSI)

Natasha Johnson (NASA GSFC)

Noam Izenberg (JHU/APL)

Erika Kohler (NASA GSFC)

Paul Mahaffy (NASA GSFC)

Charles Malespin (NASA GSFC)

Alex Pavlov (NASA GSFC)
Stephen Kane (UC Riverside)

Walter Kiefer (LPI)

Ralph Lorenz (JHU/APL)

Mike Ravine (MSSS)

Jacob Richardson (NASA GSFC)

Melissa Trainer (NASA GSFC)

Chris Webster (NASA JPL)

Mikhail Zolotov (ASU)

August 15, 2020 Submitted to the National Academies of Sciences as a Mission White Paper for the 2023-2032 Planetary Sciences \& Astrobiology Decadal Survey 


\section{EXECUTIVE SUMMARY}

The deep atmosphere of Venus is largely unexplored and yet may harbor clues to the evolutionary pathways for a major silicate planet with implications across the solar system and beyond. In situ data is needed to resolve significant open questions related to the evolution and present-state of Venus, including questions of Venus' possibly early habitability and current volcanic outgassing. Deep atmosphere "probe-based" in situ missions carrying analytical suites of instruments are now implementable in the upcoming decade (before 2030), and will both reveal answers to fundamental questions on Venus and help connect Venus to exoplanet analogs to be observed in the JWST era of astrophysics.

\section{INTRODUCTION AND BACKGROUND}

\section{The Challenge of Measuring Venus' Massive Atmosphere}

Previous Venus exploration has led to significant advancements in our understanding of the geodynamics and bulk atmospheric composition of the planet [Grinspoon \& Bullock, 2007; Kane et al., 2019; Way \& Del Genio, 2020; Lammer et al., 2020], even as profound questions remain such as those concerning atmospheric chemical stratification, possible signatures of present-day geologic and chemical activity, as well as Venus evolution. Compositional constraints from orbital nearIR night-side imaging have further produced new perspectives on the possible existence of "evolved" high-silica lithologies on Venus at scales of $\sim 100 \mathrm{~km}$ [Hashimoto et al., 2008; Gilmore et al., 2015; Gilmore et al., 2017; Weller \& Kiefer, 2020], and high priority ancient terrains are ready to be interrogated. Plans for next-generation radar and night-side near IR emission spectrometers for mapping the surface at scales from tens of meters (SAR) to $\sim 70 \mathrm{~km}$ (NIR) call for missions in the 2030s such as ESA's EnVision that will determine compositional patterns at regional to global scale for advancing models of Venus' crustal evolution [Ghail et al., 2018].

Absence of compositional and dynamical information for the deepest atmosphere including noble gas, water, and major atmospheric isotopes and the basic T-P profile places limits on present understanding of Venus, such as outlined in Weller and Kiefer (2020), with connections to the role of past oceans [Donahue et al., 1982; Kasting 1988; Way et al., 2016; Way $\&$ Del Genio, 2020]. This fundamental knowledge gap can be effectively treated in the next decade via a new class of in situ mission, embracing key aspects of the VISE concept described in the 2011 NAS Decadal Survey [V\&V, 2011] and recent VEXAG documents [VEXAG Goals, 2020]. Thanks to advancements in compact analytical instrumentation, high sensitivity descent imaging systems, and FPGA-enhanced probe flight systems, deep atmosphere "probes" are ready now to an-

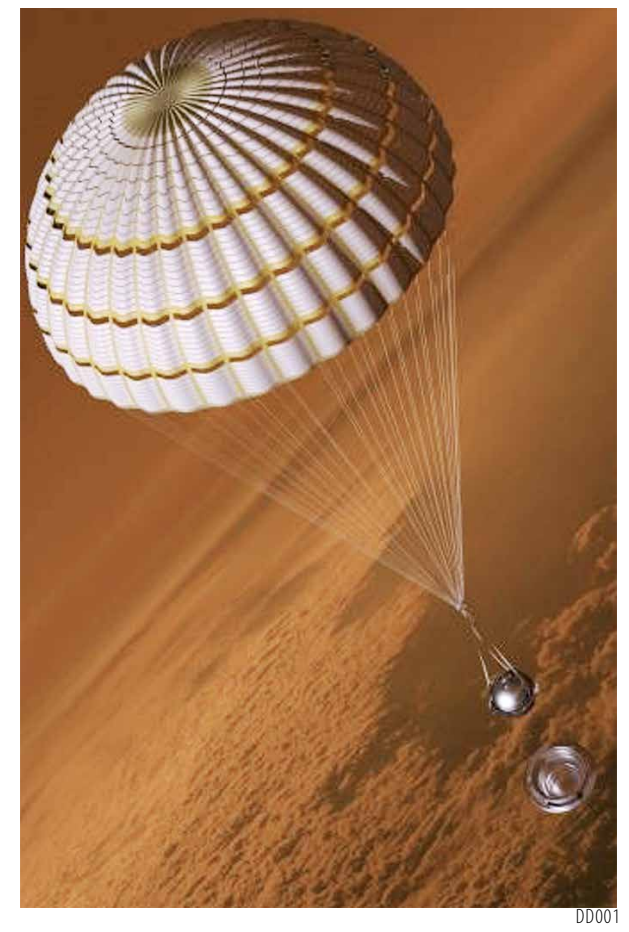

Figure 1: Conceptual Venus deep atmosphere probe mission for the 2020's decade. Such a mission could employ parachutes within the cloud deck (50-70 km) to enable time for gas ingest and processing and then freely fall to the surface at $10-15 \mathrm{~m} / \mathrm{s}$ as it images the surface in the Near Infrared (NIR) windows to permit compositional mapping while profiling trace gases down to the surface (in their environmental context). swer the top priority next questions posed by Venus in ways not possible for the past $\sim 35$ years. The case for such a "deep atmosphere probe with analytical chemistry" has been articulated since the 1983 Solar System Exploration Committee analysis [Morrison \& Hinners, 1983] as the mission to follow the radar mapper Magellan and in all intervening planetary decadal surveys [NFSS, 2002; V\&V, 2011]. Without definitive compositional measurements of Venus atmosphere down to its presently uninhabitable surface, advancements in models of its thermal and climate evolution will be impossible, thereby limiting the impact of our sister planet on our knowledge of solar system evolution (Figure 1). This mission White Paper describes the case for this class of mission concept (DEep Atmosphere Probe: DEAP) to resolve these knowledge gaps for the upcoming decade. 


\section{Deep Atmosphere of Venus Probe as a Mission Priority for the Upcoming Decade}

\section{Composition of the Venus Atmosphere: the Essential Next Step in Venus Exploration}

The Venus atmosphere holds clues to its origin, evolution, and dynamics and how it reflects the history of putative past oceans and active volcanism [Baines et al., 2013; Bougher et al., 1989; Treiman 2007; Garvin et al., 2020]. The late-1970's measurements from Pioneer Venus (PVLP) were incomplete and did not offer the precision to measure the noble gases, especially Xenon and Helium [Lammer et al., 2020], leaving ambiguities in our understanding of the planet. The single mid-atmosphere $\mathrm{D} / \mathrm{H}$ value $(\sim 150)$ was suggestive of a large water inventory that was lost [Donahue et al., 1982], but did not survey the variability in this key value from the top of the atmosphere to the near surface. No complete inventory of diagnostic trace gases was accomplished, especially for the deep atmosphere from $\sim 16 \mathrm{~km}$ to the surface, where most $(66 \%)$ of the atmosphere resides [Bougher et al., 1989]. The lapse rate (temperature as a function of altitude) is insufficiently constrained and represents a key variable for current models of the deep atmosphere, where dominant $\mathrm{CO}_{2}$ is super-critical [Lebonnois \& Schubert, 2017]. No systematic compositional cross-section as a function of altitude from the midatmosphere clouds to the surface has ever been achieved. Without definitive compositional measurements of the bulk and lower-most Venus atmosphere, essential boundary conditions for evolutionary models that seek to explain Venus as a "system" cannot be developed [Kane et al., 2019, Figure 2]. The composition of the near-surface atmosphere is needed to constrain the chemical alteration of surface materials and exchange of volatiles in the coupled atmosphere-surface rocks system [Zolotov, 2018, 2019]. Venus stands out as the least well-measured large atmosphere in the solar system (Lammer and others 2020), further limiting what our nearest neighbor planet can tell us about habitability of Earthlike planets and the broader workings of our solar system and planetary systems beyond [Kane et al., 2019; NAS Exoplanets Strategy, 2018; Way et al., 2016].
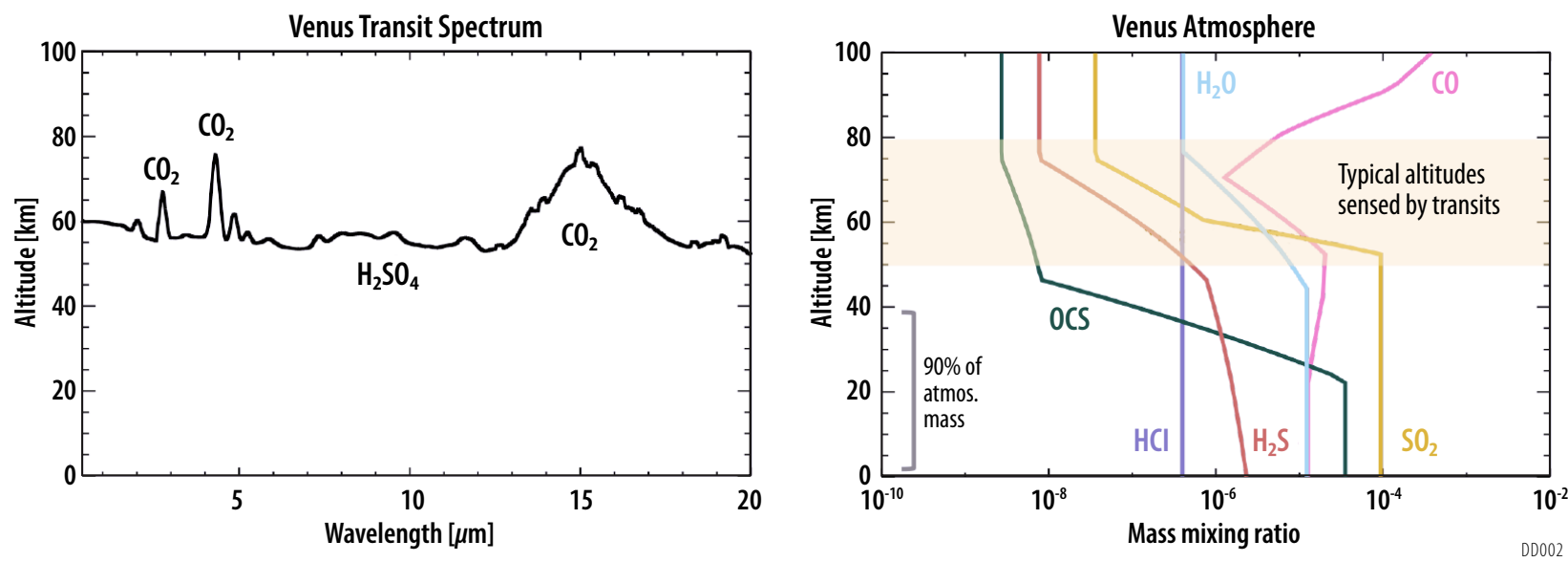

Figure 2: Greater understanding of Venus will provide higher fidelity simulations and data interpretation of what an exo-Venus might resemble to a future astrophysical observatory such as JWST or others planned for the 2030s versus the poorly-constrained Venus atmosphere (right), where most of the trace gas contents are uncertain, especially below $\sim 45 \mathrm{~km}$ (i.e., below the clouds) [Kane et al., 2019]. A conceptual DEAP mission could survey details of the composition from $70 \mathrm{~km}$ to the surface to quantify what future transiting exoplanetary spectroscopy telescopes (JWST etc.) can evaluate beyond our solar system. Deep-atmosphere data is needed to constrain and validate models attempting to understand whole-atmosphere conditions of Venus-like exoplanets.

\section{The history of habitability at Venus?}

One of the most exciting emerging justifications for Venus cloud-deck compositional measurements are their critical role in assessing past or present habitability (and potential for biological activity). Cloud-deck microbial metabolism has become increasingly recognized as a significant venue for biology in a variety of Earth environments, including the stratosphere. Limaye and others (2018) summarized the case for scenario on present-day Venus, with specific indicator species such as phosphine $\left(\mathrm{PH}_{3}\right)$ as a detectable biosignature at Venus and in spectroscopy of exoplanets [Sousa-Silva et al., 2020]. This scenario implies the in situ detectability of biogenic trace gases within the environmentally habitable cloud deck ( 50-60 km altitude) today. Chemical signatures dating for Venus' oceanic period (or 


\section{Deep Atmosphere of Venus Probe as a Mission Priority for the Upcoming Decade}

more recently) would be detectable with suitably sensitive analytical instrumentation of the type that have conducted related investigations on Mars as part of the Curiosity rover (as an example) for the past $8+$ years [Trainer et al., 2019]. Such instrumentation was largely non-existent 20 years ago but on the basis of investments that high sensitivity mass spectrometers (far exceeding the level of sensitivity enabled by remote sensing) on such missions as Curiosity (SAM) and Cassini/Huygens (INMS and GCMS), bringing such sensors to the "samples" throughout the Venus atmosphere (Figure 1) is now possible.

\section{GOALS AND RELEVANCE}

We define the comprehensive survey of the definitive composition, dynamics, and environment of the Venus atmosphere ( $70 \mathrm{~km}$ to surface) as a primary science goal for Venus exploration in the next decade [V\&V, 2011; VEXAG Goals, 2020]. Trace gases within the deepest atmosphere (i.e., 16 $\mathrm{km}$ to the surface), $\mathrm{D} / \mathrm{H}$ in water, as well as Xe and $\mathrm{He}$ are particular targets of interest due to their relevance to climate, history, putative biology, and to surface weathering regimes [Fegley et al., 1997; Zolotov, 2019]. Importantly, gradients in particular species across altitude bands (and hence as a function of pressure and temperature) provide insight into processes that connect the surface to the deep atmosphere over time scales relevant to major transitions [Weller \& Kiefer, 2020; Way \& Del Genio, 2020]. Thus, trace gas concentrations should be investigated across the entire sub-cloud atmosphere to dramatically extend current abundance data and improve understanding of the active mechanisms (thermochemical and photochemical reactions among gases, volcanism, chemical weathering, lateral variations) across the planet.

The comprehensive measurement of the Venus atmosphere is the logical next step from the perspectives of astrobiology and climatology [e.g., Kane et al., 2019; NAS Exoplanets Strategy, 2018]. Inventorying the distribution of altitude-dependent trace gases, as has been achieved at Titan and for Mars, is identified as a direct approach to detect volcanic activity and search for clues to major environmental transitions at regional to planetary scales. In-depth understanding of Venus trace gases can help to determine the roles of known and unknown processes (e.g., volcanic, thermochemical (gas-gas, gas-solid), photochemical, biological?) in controlling the current atmospheric composition to better constrain and refine relevant models beyond the current state-of-the-art [Table 1]. The updated 2020 VEXAG Goals state that determining sources and sinks of atmospheric trace gases are an essential objective for Venus, and in association with the New Frontiers "VISE" mission definition [V\&V, 2011].

Significantly, definitive measurements of the bulk and trace atmosphere at relevant, representative altitudes $(<60 \mathrm{~km})$ [Peplowski et al., 2020] can provide missing boundary conditions for evolutionary models, as emphasized by Kane and others (2019) and Way and Del Genio (2020). As the VEXAG goals explicitly state, our knowledge of trace gas sources, sinks, and abundance across the entire Venus atmosphere remains far too limited. Additional measurements from beneath the cloud-deck to the surface, including near infrared compositional and "topographic" imaging [Garvin et al., 2018, 2020], can connect the unknown trace gas contents and gradients to the local-to-regional geology of the surface in key regions that are themselves diagnostic of global-scale evolution in space and time [Weller $\&$ Kiefer, 2020], including complex ridged terrains. Picking up where Pioneer Venus Large Probe (PVLP) and the Soviet Venera and Vega landers left off, a deep atmosphere probe capable of profiling the trace gases from the clouds to the surface while measuring key environmental parameters and establishing ground truth in comparison to remote spectroscopy is amply justified.

\section{SCIENCE OBJECTIVES}

We define three primary science goals/objectives and associated measurements for quantifying the atmosphere of Venus from an in situ point of view in Table 1 for a deep atmosphere probe (DEAP).

\section{Objective 1: Origin and Diversity of Atmosphere-bearing Planets}

Venus' atmosphere is an unexplored reservoir for comparing evolutionary pathways for large-atmosphere planets, and for connecting results to ongoing and upcoming studies of exoplanets, including those accessible to the James Webb Space Telescope (JWST).

Objective 2: Evolution of Planetary Atmospheres and Habitability

Understanding the history of water and other volatiles (including those involving $S$ ) for Venus from 


\section{Deep Atmosphere of Venus Probe as a Mission Priority for the Upcoming Decade}

multi-altitude measurements of $\mathrm{D} / \mathrm{H}$ and noble gas isotopes has the potential for transforming models of Venus oceanic state in space and time.

Objective 3: Atmosphere/Surface Composition for Climate Relevance

Compositional constraints on local to regional surface geology will address the role of water in both formation (e.g., the role of water in the petrology of felsic rocks), as well as erosional and sedimentary processes that may have operated as tectonic regimes migrated over time on Venus.

Table 1: Connecting the current Planetary Decadal Survey [V\&V, 2011] science goals and objectives to what a deep atmosphere probe at Venus (DEAP*) could provide in the upcoming decade. Suggested instruments from studies including Glaze et al. (2017) and Garvin et al. (2020). Please see also VEXAG Goals (2020) and text for details.

\begin{tabular}{|c|c|c|c|c|c|}
\hline $\begin{array}{l}\text { NAS Decadal } \\
\text { Inner Planet } \\
\text { Science Goals }\end{array}$ & $\begin{array}{l}\text { NAS Decadal Inner Planet } \\
\text { Fundamental Science } \\
\text { Objectives }\end{array}$ & New Frontiers VISE Objectives & DEAP* & $\begin{array}{c}\text { Key } \\
\text { Measurements }\end{array}$ & $\begin{array}{l}\text { Example } \\
\text { Instruments }\end{array}$ \\
\hline \multirow{3}{*}{$\begin{array}{l}\text { Understand } \\
\text { the Origin and } \\
\text { Diversity of } \\
\text { Terrestrial Planets }\end{array}$} & $\begin{array}{l}\text { Constrain Bulk Composition of the } \\
\text { Terrestrial Planets to Understand } \\
\text { Formation from the Solar Nebula } \\
\text { and Evolution }\end{array}$ & $\begin{array}{l}\text { Understand the Physics and Chemistry of Venus' } \\
\text { Atmosphere, Abundances of its Trace Gases, } \\
\text { Sulfur, Light Stable Isotopes, and Noble Gas } \\
\text { Isotopes }\end{array}$ & Meets & $\begin{array}{l}\text { Noble gases \& } \\
\text { isotopes }\end{array}$ & QMS \\
\hline & \multirow{2}{*}{$\begin{array}{l}\text { Characterize Planetary Surfaces } \\
\text { to Understand Modification by } \\
\text { Geologic Processes }\end{array}$} & $\begin{array}{l}\text { Understand the Physics and Chemistry of Venus' } \\
\text { Crust, and its possible evolutionary pathways } \\
\text { across time }\end{array}$ & $\begin{array}{l}\text { Partially } \\
\text { Meets }\end{array}$ & $\begin{array}{l}\text { Composition } \\
\text { (surfaces) }\end{array}$ & $\begin{array}{l}\text { NIR Descent } \\
\text { Camera }\end{array}$ \\
\hline & & $\begin{array}{l}\text { Understand Weathering Environment of the } \\
\text { Crust of Venus in the Context of Dynamics of the } \\
\text { Atmosphere and the Composition and Texture } \\
\text { of Surface Materials }\end{array}$ & Meets & $\begin{array}{l}\text { Composition } \\
\text { (deep atmos. \& } \\
\text { surface) }\end{array}$ & $\begin{array}{l}\text { QMS }+ \text { TLS }+ \\
\text { NIR descent } \\
\text { camera }\end{array}$ \\
\hline $\begin{array}{l}\text { Understand How } \\
\text { the Evolution of } \\
\text { Terrestrial Planets } \\
\text { Enables and Limits } \\
\text { the Origin and } \\
\text { Evolution of Life }\end{array}$ & $\begin{array}{l}\text { Understand the Composition and } \\
\text { Distribution of Volatile Chemical } \\
\text { Compounds }\end{array}$ & $\begin{array}{l}\text { Understand the Properties of Venus' } \\
\text { Atmosphere down to the Surface and Improve } \\
\text { Our Understanding of Zonal Cloud-Level Winds }\end{array}$ & $\begin{array}{l}\text { Partially } \\
\text { Meets }\end{array}$ & $\begin{array}{l}\text { Trace gases and } \\
\text { environmental } \\
\text { context }(p, T)\end{array}$ & $\begin{array}{l}\text { QMS with } \\
\text { acceler- } \\
\text { ometer and p, } \\
\text { T sensors }\end{array}$ \\
\hline \multirow{3}{*}{$\begin{array}{l}\text { Understand the } \\
\text { Processes that } \\
\text { Control Climate on } \\
\text { Earth-Like Planets }\end{array}$} & $\begin{array}{l}\text { Determine How Solar Energy } \\
\text { Drives Atmospheric Circulation, } \\
\text { Cloud Formation, and Chemical } \\
\text { Cycles that Define the Current } \\
\text { Climate on Terrestrial Planets }\end{array}$ & $\begin{array}{l}\text { Constrain the Coupling of Thermochemical, } \\
\text { Photochemical, and Dynamical Processes in } \\
\text { Venus's Atmosphere and Between Surface and } \\
\text { Atmosphere to Understand Radiative Balance, } \\
\text { Climate, Dynamics, and Chemical Cycles }\end{array}$ & Meets & $\begin{array}{l}\text { Trace gas } \\
\text { composition and } \\
\text { isotope ratios in } \\
\mathrm{C}, \mathrm{H}, \mathrm{N}, \mathrm{O}, \mathrm{S}\end{array}$ & QMS + TLS \\
\hline & $\begin{array}{l}\text { Characterize Record of and } \\
\text { Mechanisms for Climate } \\
\text { Evolution on Venus, with Goal of } \\
\text { Understanding Climate Change } \\
\text { on Terrestrial Planets, Including } \\
\text { Anthropogenic Forcings on Earth }\end{array}$ & $\begin{array}{l}\text { Look for Planetary-Scale Evidence of Past } \\
\text { Hydrological Cycles, Oceans, and Life and for } \\
\text { Constraints on Evolution of the Atmosphere of } \\
\text { Venus }\end{array}$ & Meets & $\begin{array}{l}\text { Noble and trace } \\
\text { gas composition, } \\
\text { isotope ratios, } \\
\text { D/H, surface } \\
\text { composition }\end{array}$ & $\begin{array}{l}\text { NIR descent } \\
\text { camera + TLS } \\
+ \text { QMS }\end{array}$ \\
\hline & $\begin{array}{l}\text { Constrain Ancient Climates } \\
\text { on Venus and Search for Clues } \\
\text { into Early Terrestrial Planet } \\
\text { Environments to Understand Initial } \\
\text { Conditions and Long-Term Fate of } \\
\text { Earth's Climate }\end{array}$ & $\begin{array}{l}\text { Indirect VISE Objective (but part of VEXAG } 2020 \\
\text { goals) for New Frontiers }\end{array}$ & Meets & $\begin{array}{l}\text { D/H, Noble gas } \\
\text { composition } \\
\text { and isotope } \\
\text { ratios, trace gas } \\
\text { composition, } \\
\text { surface } \\
\text { composition }\end{array}$ & $\begin{array}{l}\text { QMS, TLS, } \\
\text { NIR descent } \\
\text { camera }\end{array}$ \\
\hline
\end{tabular}

\section{PRIORITY ATMOSPHERIC ENTRY TARGET SITE TYPES}

As atmosphere-surface interactions are relevant globally across the surface of Venus [Zolotov 2018], there is a large degree of flexibility in choosing any site for entry-descent and atmospheric transect science with descent imaging for composition. A wide variety of highlands regions would be compelling from Maxwell Montes to isolated tesserae such as Alpha Regio and Tellus Regio [Gilmore et al., 2015]. Revisiting previously investigated regions (PV probes, Venera, Vega landers) could also be beneficial for 


\section{Deep Atmosphere of Venus Probe as a Mission Priority for the Upcoming Decade}

the purpose of building upon preexisting results. Given lack of chemical, surface texture, and lithology data for elevated highlands known as tesserae, having at least one deep atmosphere probe with nearsurface imaging and trace gas composition would be desirable [Glaze et al., 2017].

\section{MISSION STRATEGIES}

The proven track record of successful noble and trace gas measurements at Titan (Huygens) combined with well understood techniques for comprehensive atmospheric characterization in Martian environments [Curiosity SAM: Trainer et al., 2019] make this a highly achievable mission concept for development in the next decade. A successful mission prioritizing atmospheric composition from $\sim 70$ $\mathrm{km}$ to the surface will require: (1) analytical instrumentation to measure gases with high sensitivity and signal-to-noise, (2) robust infrastructure to ingest, isolate, and process gases for measurement, (3) probe flight systems necessary to enable nadir-looking descent imaging for composition and topographic terrain analysis, and (4) entry systems to ensure an encapsulated probe flight system with suitable parachutes to enter and descend through the atmosphere over a surface region of interest at scales of $\sim 350 \mathrm{~km} \times 100 \mathrm{~km}$ (typical landing error ellipse at Venus from previous missions). On the basis of recent mission concept proposals and investments by spacefaring agencies, such a deep atmosphere probe flight system (Figure 1) with instruments and necessary avionics and telecommunications systems is implementable in the upcoming decade.

\section{(1) Detection Instrumentation:}

High-sensitivity noble and trace gas measurements, as have been demonstrated for over 8 years on Mars (and during probe descent at Titan) are available with flight-proven deep space experience, including Quadrupole Mass Spectrometers (QMS), Tunable Laser Spectrometers (TLS), and other varieties of gas-phase and aerosol analytical systems. Table 1 documents traceability to science goals. Science objectives require $\sim 1$ ppbv limits of detection, with high-precision isotopic analytical capabilities for key atmospheric species.

\section{(2) Probe Infrastructure:}

Given past flight experience (Cassini's Huygens probe, and PV Large Probe), a deep atmosphere probe mission would require multiple redundant inlets for gas ingest and processing, necessary optical viewports (e.g., sapphire) for instruments such as nadir-pointing descent imaging systems, penetrations to permit atmospheric structure and environmental measurements (p, T, accelerations), and additional penetrations for S-band radio-frequency telecommunications systems for data relay to supporting spacecraft (for ultimate downlink to Earth). These components have been demonstrated in planetary atmospheres (Mars, Venus, Titan, and Jupiter) and represent a low-technical risk approach for Venus.

\section{(3) Special Probe Flight System Support Requirements}

Beyond the capability of environmentally isolating analytical instruments from the Venus atmospheric environment for up to $\sim 1.5$ hours of descent, high optical through-put windows for descent imagers and other possible sensors (spectrophotometers) require relatively large port diameter (tens of $\mathrm{mm}$ ). Descent imaging for composition and topography has yet to be performed at Venus, but experience from DISR on the Titan Huygens probe [Soderblom et al., 2007] have demonstrated the potential of this approach. A nadir-pointed descent imaging system with near IR bands that permit surface radiance to be measured from below the clouds to the surface will permit discrimination of broad compositional trends ranging from high-silica rocks (felsic) to surfaces coated with alteration products such as hematite [Filiberto et al., 2020; Zolotov 2018], and weathered basalts. Figure 3 illustrates this potential at Venus, providing compositional assessment at scales from $5 \mathrm{~m}$ (at altitudes below $\sim 2 \mathrm{~km})$ to $100 \mathrm{~m}$ at higher altitudes $(25 \mathrm{~km})$. Combining compositional discrimination of endmember lithologies with 3D perspectives by processing of multi-frame, overlapping descent imaging [Garvin et al., 2018] will provide first-of-its-kind geological characterization tied to lower atmosphere trace gas chemistry which may be in disequilibrium [Zolotov, 2018; Lebonnois \& Schubert, 2017], thus, bringing lander/rover scale observations to Venus without the requirement for safe landings as a precursor to New Frontiers-class lander missions being considered for the 2030s [Garvin et al., 2020]. 

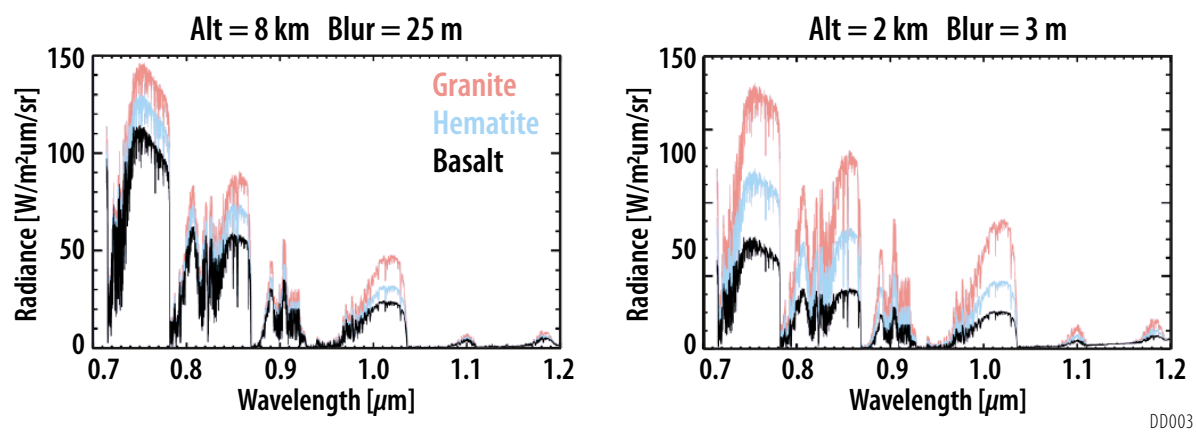

Figure 3: High-sensitivity descent imaging can discriminate between end-member rock types; 8 km (LEFT) and 2 km (RIGHT) altitudes shown, illustrating how readily felsic rocks can be distinguished even with the Rayleigh scattering and blur due to the massive Venus atmosphere. Mapping felsic rock units in the Venus highlands (tesserae) at scales from $100 \mathrm{~m}$ down to $5 \mathrm{~m}$ over areas as large as $25 \times 25 \mathrm{~km}^{2}$ is possible from a DEAP mission using descent camera technologies that have been demonstrated at Mars and Titan, and may be related to the role of water in rock formation and erosion [Gilmore et al., 2015; Hashimoto et al., 2008; Filiberto et al., 2020].

\section{CONCLUSION}

Venus' atmosphere from the top of the cloud deck near $70 \mathrm{~km}$ to the surface presents a spectacular planetary laboratory that has remained largely unexplored. Ever since 1983 and the first prioritization of NASA planetary exploration missions [Morrison \& Hinners, 1983], there has been a widelyrecognized need for a deep atmosphere probe to Venus, which was echoed in the two most recent planetary Decadal Surveys. The case for such a mission in the decade of the 2020's is now more urgent as exoplanetary observations and models point to Venus-analog planets being commonplace beyond our solar system [NAS Exoplanets Strategy, 2018].

\section{REFERENCES CITED}

Baines, K. H., et al (2013) in Climatology of Terrestrial Planets. (Eds. S. Mackwell, A. Simon, J.W. Harder, and M. Bullock). Univ. Arizona Press, Tucson, pp. 137-160.

Bougher S. W., et al..(1989) Venus II, Univ. of Arizona Press, Tucson.

Donahue T. et al. (1982) Science 216, 630-633

Donahue T. M. \& Hodges R. R. (1993) Geophysical Research Letters, 20: 591-594

Fegley Jr., B., et al. (1997) Geochemistry of surface atmosphere interactions on Venus. in Venus II: Geology, Geophysics, Atmosphere, and Solar Wind Environment (p. 591).

Filiberto, J., et al. (2020) Science Advances 6, eaax7445.

Garvin, J. B., et al. (2018) 49th Lunar and Planetary Science Conference, Abstract \#2287 Houston, TX.

Garvin, J. B. et al. (2020) DAVINCI+: Deep Atmosphere of Venus Investigation of Noble Gases, Chemistry, and Imaging Plus. 51st Lunar and Planetary Science Conference, Abstract \#2599

Ghail, Richard et al. (2017) International Journal of Applied Earth Observation and Geoinformation. 64. 10.1016/j.jag.2017.02.008.

Gilmore M. et al. (2015) Icarus 254, 350-361

Gilmore M., et al. (2017) Space Science Reviews, 212: 1511-1540; 10.1007/s11214-017-0370-8

Glaze L. S., et al. (2017) in: 2017 IEEE Aerospace Conference, vol. IEEE, pp 1-5.

Grinspoon, D. H. (1993) Nature, 363 (6428), 428-431

Grinspoon D., \& Bullock M. (2007) In: Exploring Venus as a Terrestrial Planet, pp 191-206.

Hashimoto, G. L., et al. (2008) Journal of Geophysical Research, 113(E9): CiteID E00B24.

Kasting, J. F. (1988) Runaway and moist greenhouse atmospheres and the evolution of Earth and Venus. Icarus 74, 472-494 


\section{Deep Atmosphere of Venus Probe as a Mission Priority for the Upcoming Decade}

KaneS. R., etal. (2019) Journal of Geophysical Research: Planets, 124: 2015-2028.10.1029/2019je005939

Lammer H. et al. (2020) Space Sci Rev 216:74; https://doi.org/10.1007/s11214-020-00701-x.

Lebonnois, S. \& Schubert., G (2017) Nature Geosci. 10, 473-477 (2017).

Limaye S. S., et al. (2018) Astrobiology, 18: 1181-1198; doi10.1089/ast.2017.1783

Morrison D. \& N. W. Hinners (1983) Science 220 (4597), p. 561-567.

National Academies of Sciences, Engineering, and Medicine (2018) Exoplanet Science Strategy. Washington, DC: The National Academies Press. https://doi.org/10.17226/25187.

New Frontiers in the Solar System (NFSS): An Integrated Exploration Strategy (2003) National Research Council of the National Academies, National Academies Press.

Peplowski P. N. et al. (2020) Nature Astronomy Letters, https://doi.org/10.1038/s41550-020-1079- .

Soderblom L. et al. (2007) Planetary and Space Science 55, pp. 2015-2024.

Sousa-Silva C., et al. (2020) Astrobiology, 20: 235-268.10.1089/ast.2018.1954

Trainer,M., etal. (2019)JournalofGeophysicalResearch:Planets, 124:3000-3024.10.1029/2019je006175

Treiman, A. H. (2007) in Exploring Venus as a Terrestrial Planet. (eds.: L. Esposito, E.

R. Stofan and T. E. Cravens), Geophysical Monograph Series. 176: 250, pp. 176-250.

VEXAG (2020) Venus Scientific Goals, Objectives, Investigations, and Priorities: 2020. (Venus Exploration Program Analysis Group (VEXAG).

Visions and Voyages (V\&V) for Planetary Science in the Decade 2013-2022 (2011) National Research Council of the National Academies, National Academies Press.

Way M. J., et al. (2016) Geophysical Research Letters, 43: 8376-8383

Way, M. J., \& Del Genio, A. D. (2020) Journal of Geophysical Research: Planets, 125, e2019JE006276. https://doi.org/10.1029/2019JE006276

Weller, M. B., \& Kiefer, W. S. (2020) Journal of Geophysical Research: Planets, 125, e2019JE005960. https://doi.org/10.1029/2019JE005960

Zolotov, M. Y. (2018) Reviews in: Mineralogy and Geochemistry, 84(1), 351-392.

Zolotov M. (2019) Chemical weathering on Venus. In Oxford Research Encyclopedia of Planetary Science. Oxford University Press. http://dx.doi.org/10.1093/acrefore/9780190647926.013.146. 